\title{
Sistem Pakar Diagnosa Gangguan Pencernaan Pada Manusia Menggunakan Metode Certainty Factor
}

\author{
Desi Endiyana Purba ${ }^{1}$, R. Mahdalena Simanjorang ${ }^{2}$ \\ Program Studi Teknik Informatika, STMIK Pelita Nusantara \\ Jl. Iskandar Muda No. 1 Medan \\ desypurba17@gmail.com, lenasinaga30@gmail.com
}

\begin{abstract}
Along with advances in science and technology, especially in the field of medicine, more sophisticated medical equipment will be produced in fighting disease or making early detection of disease so that treatment can be faster. One of them is digestive disorders in humans. The purpose of this study is to build an expert system application that is able to diagnose digestive disorders in humans based on the symptoms experienced by implementing the Certainty Factor method. The development of an expert system uses the waterfall model, which consists of the stages of analysis, formulating problems, collecting data, and testing. The implementation of the Certainty Factor method in this expert system is used to generate a level of confidence in the diagnosis of the disease. The expert system was tested through 3 stages of testing, namely blackbox test, validity test and user test. In the blackbox test, the system functions run as expected. In the validity test, the system is declared valid for use. In the user test, respondents gave the criteria of "Eligible". From the results of the study, it can be concluded that the system is able to provide a trust value and can diagnose digestive disorders based on the symptoms entered by the user. Because the system is still limited, it is hoped that there will be system development with other methods so that it is more useful for users.
\end{abstract}

\section{Keywords- Expert System, Digestive Disorders, Certainty Factor}

\begin{abstract}
Abstrak-Seiring dengan kemajuan ilmu pengetahuan dan teknologi khususnya dalam bidang kedokteran akan dihasilkan peralatan medis yang semakin canggih dalam memerangi penyakit atau melakukan deteksi lebih dini penyakit agar lebih cepat mendapat penanganan. Salah satunya adalah gangguan pencernaan pada manusia. Tujuan penelitian ini adalah membangun aplikasi sistem pakar yang mampu melakukan diagnosis gangguan pencernaan pada manusia berdasarkan gejala yang dialami dengan mengimplementasikan metode Certainty Factor. Pengembangan sistem pakar menggunakan model waterfall, yang terdiri dari tahap analisis, merumuskan masalah, mengumpulkan data, dan pengujian. Implementasi metode Certainty Factor pada sistem pakar ini digunakan untuk menghasilkan tingkat kepercayaan dalam diagnosis penyakit. Sistem pakar diuji melalui 3 tahap pengujian yaitu uji blackbox, uji validitas dan uji pengguna. Pada uji blackbox, fungsi sistem berjalan sesuai yang diharapkan. Pada uji validitas, sistem dinyatakan valid untuk digunakan. Pada uji pengguna, responden memberikan kriteria "Layak". Dari hasil penelitian dapat disimpulkan bahwa sistem mampu memberikan nilai kepercayaan dan dapat mendiagnosis gangguan pencernaan berdasarkan gejala yang dimasukkan user. Karena masih terbatasnya sistem, diharapkan adanya pengembangan sistem dengan metode lain sehingga lebih bermanfaat bagi pengguna.
\end{abstract}

Kata kunci-Sistem Pakar, Gangguan Pencernaan, Certainty Factor

\section{PENDAHULUAN}

Perkembangan teknologi akhir ini berkembang semakin cepat dan pola berfikir manusia pun berkembang mengikuti zaman. Begitu pula dengan perkembangan komputer. Komputer merupakan salah satu alat yang biasa kita gunakan untuk mempermudah aktivitas kerja. Perkembangan teknologi tidak akan dapat dihasilkan tanpa ada campur tangan sumber manusia untuk mengelola dan merawatnya dengan baik. Untuk mendapatkan dan menghasilkan informasi, komputer dan teknologinya adalah alat bantu yang paling tepat, salah satunya dalam memperoleh informasi tentang penyakit pencernaan.

Pencernaan merupakan serangkaian organ tubuh yang bertanggung jawab dalam proses pencernaan makanan. Pencernaan ini dapat terkena gangguan atau terinfeksi penyakit sehingga perlu diwaspadai oleh masyarakat. Oleh karena itu, penyebaran informasi tentang penyakit ini sangat diperlukan untuk mengetahui lebih dini jenis penyakit yang dideritanya. Jika penyakit yang diderita termasuk parah dan perlu pengobatan serius, tentu saja hal ini perlu segera diketahui.

Pada Klinik Kusuma Bangsa pada kurun waktu 5 tahun terakhir ada sekita $56 \%$ pasien mengalami gangguan pencernaan, diantaranya $30 \%$ Diare, $16 \%$ Radang Usus Buntu, dan 10\% Gastroentitis. Minimnya pengetahuan dan peralatan serta tenaga kerja medis dalam menangani pasien terebut maka hal ini sering dapat menimbulkan masalah dalam hal keterlambatan penanganan pasien dikarenakan antrian yang terlalu banyak. Informasi tentang penyakit pencernaan 
sebenarnya sudah tersedia, tapi masih dalam bentuk manual, yaitu dalam buku-buku atau majalah kesehatan. Seperti yang kita ketahui ada beragam jenis gangguan pada pencernaan manusia. Keberagaman gangguan pencernaan ini menjadi masalah bagi masyarakat masih awam untuk mengetahui tentang gejala-gejala penyakit gangguan pada pencernaan dan solusi yang harus dilakukan bila terkena gangguan pencernaan tersebut. Oleh karena itu diperlukan suatu sistem yang dapat mendiagnosa penyakit pencernaan tersebut, sistem tersebut adalah sistem pakar.

Metode Certainty Factor merupakan proses mengolah 2 bobot dalam sekali perhitungan. Untuk bobot yang lebih dari 2 banyaknya, untuk melakukan perhitungan tidak terjadi masalah apabila bobot yang dihitung teracak, artinya tidak ada aturan untuk mengkombinasikan bobotnya, karena untuk kombinasi seperti apapun hasilnya akan tetap sama. Untuk mengetahui apakah seorang pasien tersebut menderita penyakit kulit atau tidak, itu dilihat dari hasil perhitungan bobot setelah semua keluhan keluhan diinputkan dan semua bobot dihitung dengan menggunakan metode Certainty Factor..

\section{METODE PENELITIAN} dari:

Metode yang digunakan pada penelitian ini terdiri a. Studi Literatur

Metode studi literatur dilakukan dengan cara membaca buku referensi, jurnal, dan media lain yang berkaitan dengan pengumpulan, analisa, dan pengolahan data secara umum. Dalam hal ini adalah buku-buku atau jurnal-jurnal terkait sistem pakar dan gangguan pencernaan pada manusia.

b. Wawancara

Untuk memperoleh pengetahuan dari pakar, dilakukan dengan cara tanya jawab secara langsung kepada pakar yang memberikan solusi atau pencegahan serta penanganan terhadap penderita gangguan pencernaan secara tepat.

Tahapan perancangan dan pengembangan antara lain adalah sebagai berikut:

1. Identifikasi

Tahap identifikasi digunakan untuk menentukan batasan masalah, pakar yang terlibat, serta tujuan yang ingin dicapai.

a. Batasan masalah pada penelitian ini adalah:

- Metode yang digunakan pada penelitian ini adalah metode Certainty Factor

- Hanya mendiagnosa gangguan pencernaan dengan menampilkan gejala-gejala dan solusi penanganan awal yang harus dilakukan

- Jenis penyakit yang di bahas Radang Usus Buntu, Gastritis, dan Diare

- Sistem dibangun dengan menggunakan bahasa pemrograman PHP Dan MySQL sebagai Database Managemet System (DBMS)

b. Pakar yang terlibat adalah Dokter spesialis Pencernaan

c. Tujuan penelitian ini adalah:

- Menerapkan metode Certainty Factor untuk sistem pakar diagnosa gangguan pencernaan pada manusia.

- Merancang dan membangun sistem pakar untuk diagnosa penyakit pada sistem pencernaan sehingga dokter spesialis penyakit pencernaan dapat melakukan diagnosa dengan akurat, serta pasien mendapatkan hasil diagnosa penyakit beserta keterangan dan solusi dengan mudah dan cepat.

Definisi menurut David McAllister, Certainty Factor adalah suatu metode untuk membuktikan apakah suatu fakta itu pasti ataukah tidak pasti yang berbentuk metric yang biasanya digunakan dalam sistem pakar. Metode ini sangat cocok untuk sistem pakar yang mendiagnosis sesuatu yang belum pasti (Zulfian Azmi 2017:91). Metode Certainty Factor (CF) diusulkan oleh Shortliffe dan Buchanan pada tahun 1975 untuk mengakomodasi ketidakpastian pemikiran (inexact reasoning) seorang pakar. Seorang pakar, misalnya dokter menganalisis informasi yang ada dengan ungkapat seperti "mungkin", "kemungkinan besar", "hamper seperti". Untuk mengakomodasi hal ini kita menggunakan Certainty Factor guna menggambarkan tingkat keyakinan pakar terhadap masalah yang sedang dihadapi:

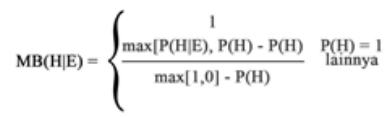

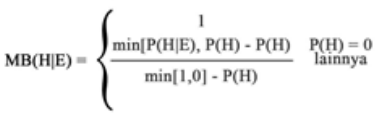

$\mathrm{CF}$

$\mathrm{MB}(\mathrm{H}, \mathrm{E})$

$\mathrm{MD}(\mathrm{H}, \mathrm{E})$

\section{HASIL DAN PEMBAHASAN}

Berdasarkan akuisisi pengetahuan dari salah seorang pakar, implementasi dalam sistem pakar berupa basis pengetahuan yang direpresentasikan dalam bentuk aturan seperti terlihat pada Tabel 1 . 
Tabel 1. Daftar Gejala Gangguan Pencernaan KODE GEJALA NAMA GEJALA BOBOT

\begin{tabular}{lll}
\hline G01 & Nyeri Perut & 0.8 \\
\hline G02 & Nafsu makan menurun & 0.6 \\
\hline G03 & Konstipasi & 0.6 \\
\hline $\begin{array}{l}\text { Nilai Leukosit biasanya } \\
\text { men }\end{array}$ & 0.8 \\
& $\begin{array}{l}\text { nilai normal dari rentang } \\
\text { nilat not }\end{array}$ & \\
\hline
\end{tabular}

Pada auskultasi, bising 0.8 usus normal atau

G05 meningkat pada awal apendisitis dan bising melemah jika terjadi perforasi

\begin{tabular}{llrl}
\hline G06 & Demam & 0.6 \\
\hline & Temuan dari hasil USG & 0.8 \\
& berupa cairan yang & \\
berada & disekitar & \\
G07 & $\begin{array}{l}\text { apendiks } \\
\text { menjadi }\end{array}$ &
\end{tabular}
sebuah tanda sonografik penting

\begin{tabular}{lll}
\multicolumn{4}{l}{ sonografik penting } \\
\hline G08 & $\begin{array}{l}\text { Nyeri yang terasa panas } \\
\text { dan perih di perut } \\
\text { bagian uluhati }\end{array}$ & \\
\hline G09 & Perut kembung & 0.6 \\
\hline G10 & Cegukan & 0.8 \\
\hline G11 & Mual & 0.6 \\
\hline G12 & Muntah & 0.6 \\
\hline G13 & Hilang nafsu makan & 0.8 \\
\hline G14 & $\begin{array}{l}\text { Cepat merasa kenyang } \\
\text { saat makan }\end{array}$ & 0.8 \\
\hline B16 & $\begin{array}{l}\text { Buang air besar dengan } \\
\text { tinja berwarna hitam }\end{array}$ & 0.6 \\
\hline M17 & Nantah darah & 0.6 \\
\hline Konsistensi tinja cair/ & 0.8 \\
encer dan berbau tidak \\
enak, kadang-kadang \\
mengandung lendir dan \\
darah
\end{tabular}

keruh tidak berbau

\begin{tabular}{lll}
\hline G25 & $\begin{array}{l}\text { Mual dan kejang pada } \\
\text { otot kaki }\end{array}$ & 0.6 \\
\hline G26 & Diare dan muntah & 0.8 \\
\hline G27 & $\begin{array}{l}\text { Diare mungkin terjadi } \\
\text { tanpa mulas dan tidak } \\
\text { mual }\end{array}$ & 0.6 \\
\hline G28 & $\begin{array}{l}\text { Bentuk feses cair dan } \\
\text { berwarna putih keruh }\end{array}$ & 0.8 \\
\hline G29 & Dehidrasi & 0.6 \\
\hline G30 & $\begin{array}{l}\text { Gejala yang timbul } \\
\text { adalah toksik diare }\end{array}$ & 0.8 \\
\hline G31 & $\begin{array}{l}\text { Tinja mengandung } \\
\text { darah dan lendir }\end{array}$ & 0.6 \\
\hline G32 & $\begin{array}{l}\text { Jarang mengakibatkan } \\
\text { dehidrasi }\end{array}$ & 0.6 \\
\hline G33 & $\begin{array}{l}\text { Febris, perut kembung, } \\
\text { anoreksia, mual dan } \\
\text { muntah muncul setiap } \\
\text { empat hari }\end{array}$ \\
\hline
\end{tabular}

Tabel 2. Jenis Gangguan Pencernaan

\begin{tabular}{cccc}
\hline $\begin{array}{c}\text { Kode } \\
\text { Penyakit }\end{array}$ & $\begin{array}{c}\text { Nama } \\
\text { Penyakit }\end{array}$ & Kronis & Akut \\
\hline P1 & $\begin{array}{c}\text { Radang } \\
\text { Usus Buntu }\end{array}$ & $10-50 \%$ & $>50 \%$ \\
\hline P2 & Gastritis & $10-50 \%$ & $>50 \%$ \\
\hline P3 & Diare & $10-50 \%$ & $>50 \%$ \\
\hline
\end{tabular}

Tabel 3. Rule Base Gangguan Pencernaan

\begin{tabular}{|c|c|}
\hline \multicolumn{2}{|c|}{ RULE BASE } \\
\hline Consequent & Antecedant \\
\hline P1 & $\begin{array}{l}\text { G01 (Nyeri Perut) and G02 } \\
\text { (Nafsu makan menurun) } \\
\text { and G03 (Konstipasi) and } \\
\text { G04 (Nilai Leukosit } \\
\text { biasanya meningkat dari } \\
\text { rentang nilai normal) and } \\
\text { G05 (Pada auskultasi, } \\
\text { bising usus normal atau } \\
\text { meningkat pada awal } \\
\text { apendisitis dan bising } \\
\text { melemah jika terjadi } \\
\text { perforasi) and } \\
\text { (Demam) and } \\
\text { (Temuan dari hasil USG } \\
\text { berupa cairan yang berada } \\
\text { disekitar apendiks menjadi } \\
\text { sebuah tanda sonografik } \\
\text { penting) }\end{array}$ \\
\hline
\end{tabular}

G08 (Nyeri yang terasa panas dan perih di perut bagian uluhati) and G09
(Perut kembung) G10 (Cegukan) and G11 (Mual) and G12 (Muntah) and G13 (Hilang nafsu makan) 
and G14 (Cepat merasa kenyang saat makan) and G15 (Buang air besar dengan tinja berwarna hitam)

G16 (Muntah darah) and G17 (Naiknya suhu tubuh) and G18 (Konsistensi tinja cair/ encer dan berbau tidak enak, kadang-kadang mengandung lendir dan darah) and G19 (Stadium prodomal berlangsung selama dua sampai 4 hari dengan gejala sakit, nyeri dan perut kembung) and G20 (Lemah) and G21 (Berat badan turun drastis) and G22 (Mulas menetap pada pasien bayi) and $\mathbf{G 2 3}$ (Rasa mulas singkat dapat terjadi sewaktu-waktu) and G24 (Konsistensi tinja encer dan mungkin berubah menjadi cairan putih keruh tidak berbau) and $\mathbf{G 2 5}$ (Mual dan kejang pada otot kaki) and G26 (Diare dan muntah) and G27 (Diare mungkin terjadi tanpa mulas dan tidak mual) and G28 (Bentuk feses cair dan berwarna putih keruh) and G29 (Dehidrasi) and G30 (Gejala yang timbul adalah toksik diare) and G31 (Tinja mengandung darah dan lendir) and G32 (Jarang mengakibatkan dehidrasi) and $\mathbf{G 3 3}$ (Febris, perut kembung, anoreksia, mual dan muntah muncul setiap empat hari)

Nilai diberikan oleh pakar, yang berfungsi untuk menentukan tingkat kepercayaan dari setiap gejala dari penyakit. Metode untuk menghasilkan kesimpulan yang digunakan dalam penelitian ini adalah Certainty Factor. Certainty factor (CF) merupakan salah satu teknik yang digunakan untuk mengatasi ketidakpastian dalam pengambilan keputusan. Metode ini diperkenalkan oleh Shortlife Buchanan pada tahun 1970-an. Metode CF ini dapat menggambarkan tingkat keyakinan seorang pakar terhadap masalah yang dihadapi. Hubungan tingkat keyakinan dengan nilai CF dapat dilihat pada Tabel 4.

Tabel 4. Tingkat Keyakinan Nilai CF

\begin{tabular}{lll}
\hline No & Keterangan & Nilai User \\
\hline
\end{tabular}

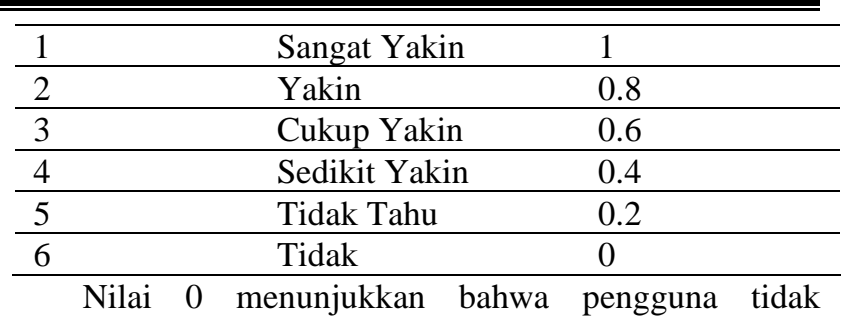
mengalami gejala seperti yang ditanyakan oleh sistem. Apabila pengguna yakin mengalami suatu gejala maka nilai user semakin tinggi pula. Biasanya suatu penyakit memiliki gejala lebih dari satu, sehingga kaidah yang digunakan adalah yang berkaitan dengan penyakit. Pada bagian ini dibuat contoh kasus dimana pengguna mengalami gejala-gejala sebagai berikut:

- $\quad$ Nyeri Perut (0.8)

- Nafsu makan menurun (0.6)

- $\quad \operatorname{Demam}(0.4)$

Dengan menggunakan metode Certainty Factor nantinya dapat diketahui penyakit yang diderita oleh pengguna. Dengan merujuk pada tabel bobot CF maka akan dihitung diagnosa yang cocok dengan gejala yang diinputkan user.

1. Radang Usus Buntu

Hasil pencocokan yang dimiliki penyakit radang usus buntu didapat data gejala yang sama yaitu:

$$
\begin{aligned}
\mathrm{G} 01 & =\text { Nyeri Perut }(0,8) \\
\mathrm{CF}[\mathrm{H}, \mathrm{E}] 1 & =\mathrm{CF}[\mathrm{H}] 1 * \mathrm{CF}[\mathrm{E}] 1 \\
& =0.8 * 0.8 \\
& =0.64 \\
\mathrm{G} 02 & =\text { Nafsu Makan Menurun }(0,8) \\
\mathrm{CF}[\mathrm{H}, \mathrm{E}] 2 & =\mathrm{CF}[\mathrm{H}] 2 * \mathrm{CF}[\mathrm{E}] 2 \\
& =0.8 * 0.6 \\
& =0.48 \\
\mathrm{G} 06 & =\text { Demam }(0,8) \\
\mathrm{CF}[\mathrm{H}, \mathrm{E}] 3 & =\mathrm{CF}[\mathrm{H}] 3 * \mathrm{CF}[\mathrm{E}] 3 \\
& =0.8 * 0.6 \\
\mathrm{CFk} 1 & =0.48 \\
{[\mathrm{H}, \mathrm{E}] 3) *(1-\mathrm{CF}[\mathrm{H}, \mathrm{E}] 1) } & =(0.64+0.48+0.48) *(1-0.64) \\
& =1.6 * 0.36 \\
& =0.576
\end{aligned}
$$

Maka CF dari gejala yang diinputkan pengguna untuk penyakit Radang Usus Buntu kemungkinannya sebesar 0.576 atau $57.6 \%$. Maka pengguna terindikasi radang usus buntu akut.

Solusi penanganan awal :

1. Hindari aktivitas berat

2. Tahan perut Anda saat batuk

3. Bangun dan bergerak saat Anda siap

4. Tidur saat Anda merasa Lelah

5. Makan makanan yang tinggi serat

6. Mencoba obat alami

7. Operasi.

Mekanisme penalaran dan perhitungan nilai $\mathrm{CF}$ kemudian dituliskan ke dalam bahasa pemrograman PHP untuk membangun sistem pakar diagnosis penyakit kulit berbasis web. Proses diagnosis penyakit kulit 
SAINTEK (Jurnal Sains dan Teknologi)

Volume 3 No. 2 | Maret 2022 : 36-42

E-ISSN : 2714-8661

dilakukan melalui antarmuka pengguna dari sistem.

Halaman awal sistem dapat dilihat pada penjelasan dibawah ini:

Penjelasan mengenai Form Login

\section{Administrator}

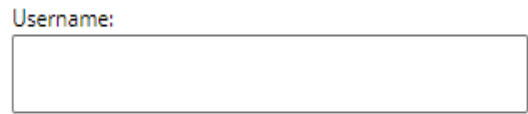

Password:

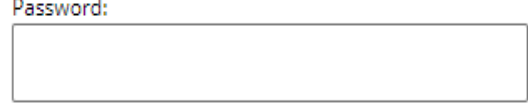

$\rightarrow$ Submit

\section{Gambar 1. Halaman Login Admin}

Pada Halaman Login ini admin harus memasukkan username dan password yang sudah ditentukan dan masuk ke sistem.

Penjelasan halaman utama admin

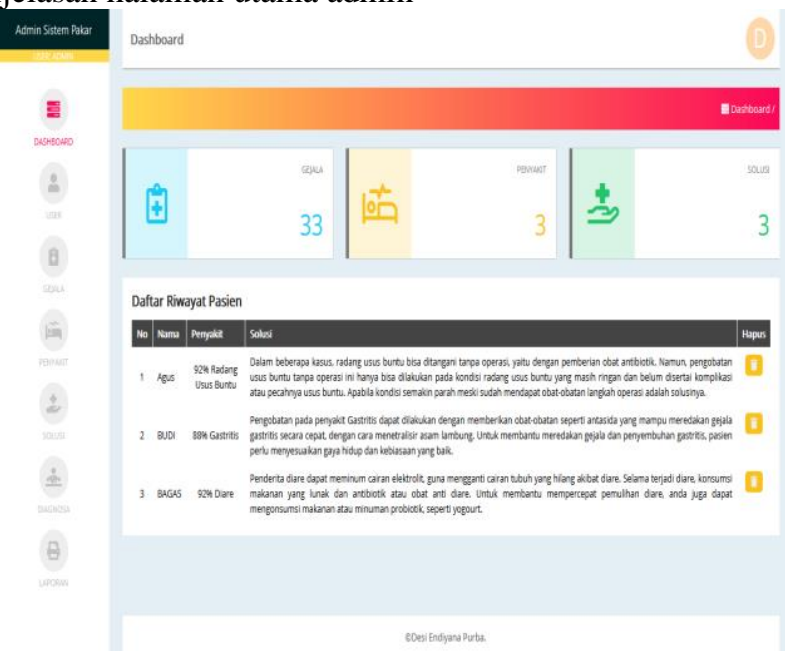

Gambar 2. Halaman Utama Admin

Pada Halama utama admin terdapat beberapa menu diantaranya, User, Gejala, Penyakit, Solusi, dan Diagnosa. Dimana di setiap menu admin dapat mengolah datanya, menambah, mengedit, dan menghapus data tersebut sesuai kebutuhan. Penjelasan halaman gejala

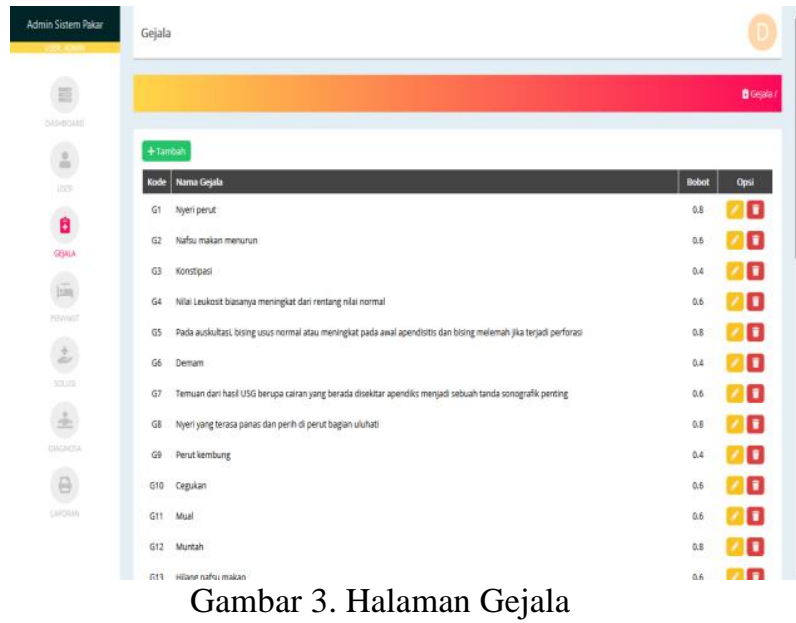

Pada halaman ini admin dapat mengolah data gejala, dimana admin dapat menambah, mengedit, dan menghapus data gejala sesuai kebutuhan sistem.

Penjelasan halaman penyakit

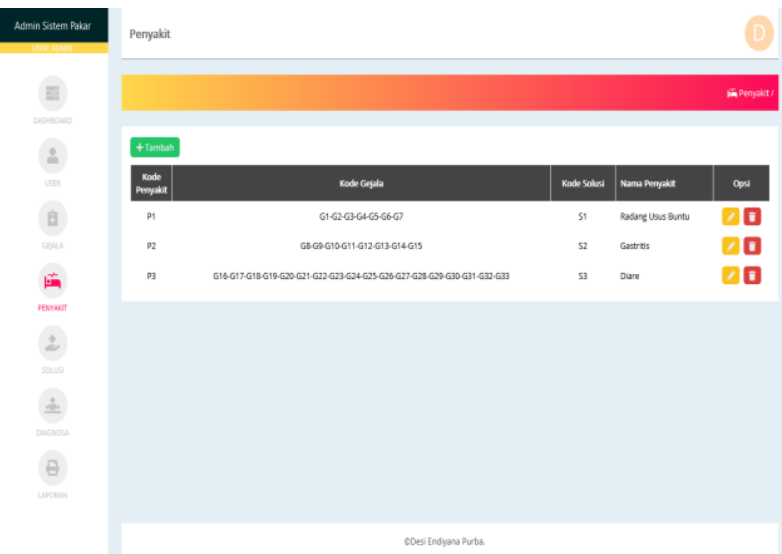

Gambar 4. Halaman Penyakit

Pada halaman ini admin dapat mengolah data penyakit, dimana admin dapat menambah, mengedit, dan menghapus data penyakit sesuai kebutuhan sistem.

\section{Penjelasan halaman Solusi}

semins statem fatar solus

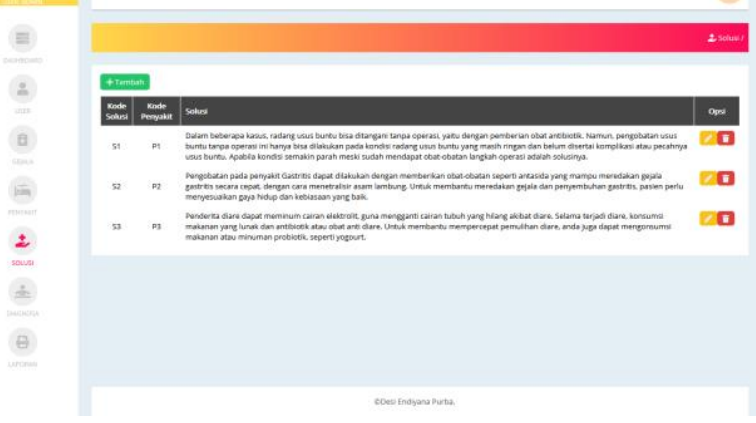

Gambar 5. Halaman Solusi 
Pada halaman ini admin dapat mengolah data solusi, dimana admin dapat menambah, mengedit, dan menghapus data solusi sesuai kebutuhan sistem.

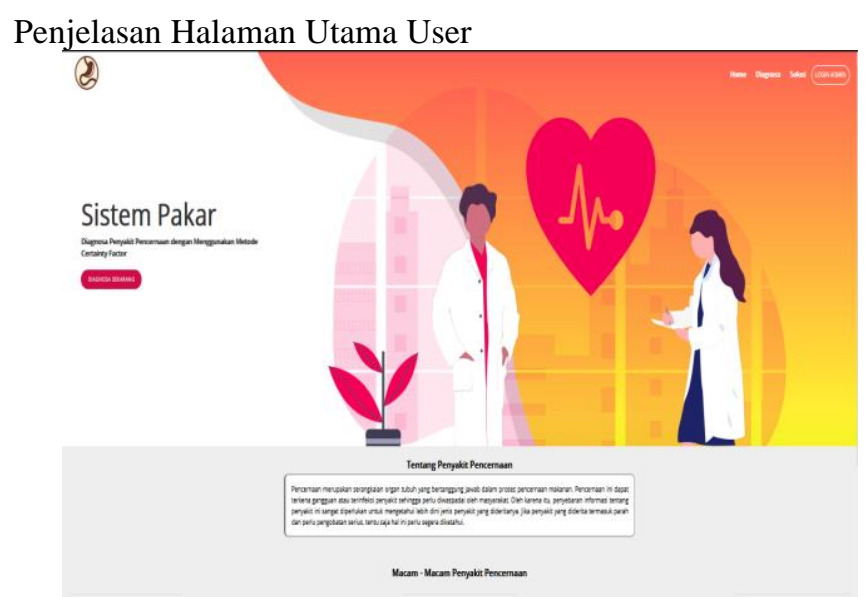

Gambar 6. Halaman Utama User/ Pasien

Pada gambar diatas dapat dijelaskan bahwa ada beberapa menu pada tampilan utama, yaitu Home dimana menu tersebut menampilkan penjelasan tentang gangguan pencernaan pada manusia dan jenis gangguan yang dibahas dalam aplikasi ini, menu Diagnosa menampilkan daftar gejala-gejala yang akan dipilih user untuk mendiagnosa penyakit jenis apa yang diderita.

Penjelasan Halaman Registrasi

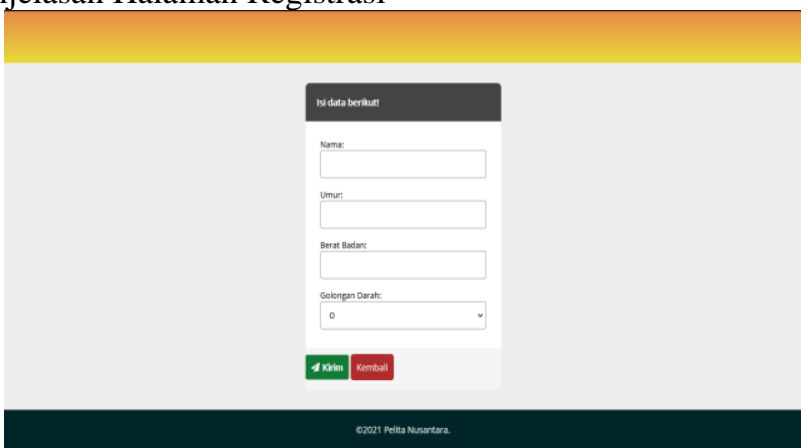

Gambar 7. Halaman Registrasi

Pada halaman registrasi user harus mengisi nama, umur, berat badan dan golongan darah, setelah mengisi data tersebut kemudian klik tombol kirim agar data pasien terinput ke sistem.

Penjelasan Halaman Diagnosa

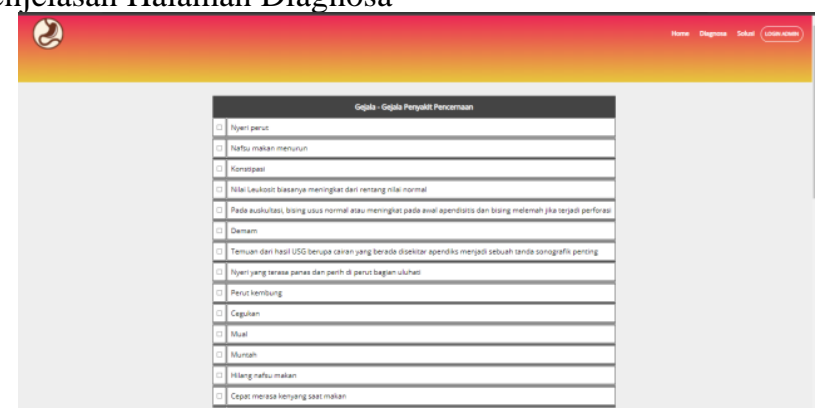

Gambar 8. Halaman Diagnosa
Pada Halaman diagnosa pasien bebas memilih gejala yang iya rasakan dan setelah memilih gejala pasien atau user bisa menekan tombol diagnosa agar sistem memproses atau mendiagnosa penyakit jenis apa yang diderita user.

Penjelasan Halaman Hasil Diagnosa

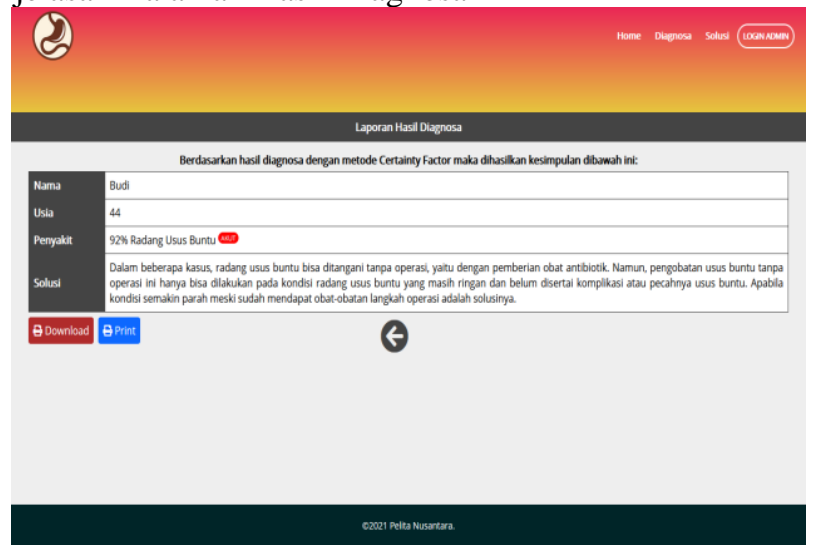

Gambar 9. Halaman Hasil Diagnosa.

\section{IV.REFERENSI}

1. Sianturi FA, Informatika M, Factor MC. Analisa Metode Centainty Factor Dalam Mendiagnosa Hama. Mantik Penusa. 2019;3(1):65-72.

2. Kusumawijaya IP. Aplikasi Sistem Pakar Kerusakan Personal Computer Menggunakan Metode Certainty Factor. ICIT Journal. 2020;6(2):183-94.

3. Wati VW, Tusaadiah H. Sistem Pakar Mendeteksi Kerusakan Pada Smartphone Dengan Metode Forward Chaining. Jurnal Sains dan Teknologi: Jurnal Keilmuan dan Aplikasi Teknologi Industri. 2017;17(2):98.

4. Artikel I. Sistem Pakar Mendiagnosa Penyakit Kucing Persia dengan Metode Teorema Bayes. 2018;1(2):15-24.

5. SIHOTANG HT, Panggabean E, Zebua H. Sistem Pakar Mendiagnosa Penyakit Herpes Zoster Dengan Menggunakan Metode Teorema Bayes. 2019;3(3):192-6.

6. Setyaputri KE, Fadlil A. Analisis Metode Certainty Factor pada Sistem Pakar Diagnosa Penyakit THT. Jurnal Teknik Elektro. 2018;10(1):30-5.

7. Sinaga B, Hasugian PM, Manurung AM. Sistem Pakar Mendiagnosa Kerusakan Smartphone. 2018;3(1):333-9.

8. Oktapiani R. Sistem Pakarmendeteksi Permasalahan Komputer Dari Beep Bios Dengan Metode Forward Chaining. Jurnal Tekno Insentif. 2017;11(Ci):43-52.

9. Aini N, Ramadiani R, Hatta HR. Sistem Pakar Pendiagnosa Penyakit Tuberkulosis. Informatika Mulawarman : Jurnal Ilmiah Ilmu Komputer. 2017; 
SAINTEK (Jurnal Sains dan Teknologi)

Volume 3 No. 2 | Maret 2022 : 36-42

E-ISSN : 2714-8661

10. Informatika JT, Informatika T, Industri SI, Informatika T, Riau PC. Sistem Pakar Diagnosa Penyakit Ginjal Menggunakan Metode. Sistem Pakar Diagnosa Penyakit Ginjal Menggunakan Metode Hill Climbing. 2012; 